\title{
Diagnosis \& Clinical Features of Pemphigus Foliaceus
}

\author{
Kirk A. James, B.S[Student Research Fellow], \\ Department of Dermatology, University of North Carolina at Chapel Hill, Mailing Address: 5101 \\ Thurston-Bowles Bldg, CB\#7287, Chapel Hill, NC 27599-7287, Phone: N/A, Fax: (919) 843-5766, \\ kirk_james@med.unc.edu \\ Donna A. Culton, M.D., Ph.D.[Assistant Professor], and \\ Department of Dermatology, University of North Carolina at Chapel Hill, Mailing Address: 414 \\ Mary Ellen Jones Bldg, CB\#7287, Chapel Hill, NC 27599-7287, Phone: (919) 966-0785, Fax: \\ (919) 966-3898, DCulton@unch.unc.edu
}

\author{
Luis A. Diaz, M.D.[Professor and Chair] \\ Department of Dermatology, University of North Carolina at Chapel Hill, Mailing Address: 5101 \\ Thurston-Bowles Bldg, CB\#7287, Chapel Hill, NC 27599-7287, Phone: (919) 843-6756, Fax: \\ (919) 843-5766, luis_diaz@med.unc.edu
}

\author{
Keywords \\ Pemphigus foliaceus; fogo selvagem; endemic; desmoglein 1; diagnosis; history
}

\section{Introduction}

\begin{abstract}
Pemphigus foliaceus (PF) is an acquired autoimmune blistering disease in which the body's immune system produces immunoglobulin $\mathrm{G}(\mathrm{IgG})$ autoantibodies that target the intercellular adhesion glycoprotein desmoglein-1 (dsg-1). The binding of these autoantibodies to dsg-1, which is principally expressed in the granular layer of the epidermis, results in the loss of intercellular connections between keratinocytes (acantholysis) and the formation of subcorneal blisters within the epidermis. The ultimate clinical manifestations of this process are fragile, superficial blisters and bullae of the cutaneous surface that easily rupture to yield erosive lesions.
\end{abstract}

The pathogenic autoantibodies of PF are of the IgG4 subclass, which has been demonstrated by their passive transfer from human sera to neonatal mice (1). These IgG4 autoantibodies recognize antigenic epitopes located on the $\mathrm{N}$-terminus of the ectodomain of dsg-1, specifically on extracellular (EC) domains 1 and $2(2,3)$. The binding of pathogenic IgG to dsg-1 triggers the phosphorylation of p38 mitogen-activated protein kinase (MAPK) which is thought to induce apoptosis of the affected keratinocyte $(4,5,6)$. Although complement component 3 (C3) deposition on direct immunofluorescence (DIF) initially suggested that it may play a role in acantholysis in PF, both C5-deficient mice and total complement-depleted

(C) 2011 Elsevier Inc. All rights reserved.

Correspondence to: Luis A. Diaz.

Publisher's Disclaimer: This is a PDF file of an unedited manuscript that has been accepted for publication. As a service to our customers we are providing this early version of the manuscript. The manuscript will undergo copyediting, typesetting, and review of the resulting proof before it is published in its final citable form. Please note that during the production process errors may be discovered which could affect the content, and all legal disclaimers that apply to the journal pertain.

Financial Disclosure/Conflict of Interest Statement:

The authors of this paper have no financial disclosures or conflicts of interest to express. 
mice still develop subcorneal vesicles upon passive transfer of pathogenic human sera (7). The pathogenesis of PF is covered in this issue in more detail by Valeria Aoki.

There are 2 predominant types of PF: idiopathic PF, which is found universally and occurs sporadically, and fogo selvagem (FS), an endemic variety linked exclusively to multiple distinct geographical areas. Other, albeit rarer, variants of PF have been described, including pemphigus erythematosus (PE, Senear-Usher syndrome) and drug-induced PF. IgA pemphigus and pemphigus herpetiformis $(\mathrm{PH})$ have previously been described in the literature as variants of PF, but appear to be distinct subtypes of the general pemphigus category, both clinically and histopathologically (8).

\section{Clinical Features}

\section{Epidemiology}

The worldwide incidence and prevalence of PF is very low, making it a rare disease. Because of the presence of endemic areas, however, these figures may vary considerably based on the specific geographical area being studied. For instance, the incidence of PF in Tunisia has been found to be as high as 6.7 new cases per million per year (9). In Brazil, which has multiple foci of endemic PF, there is a region located in the state of Maso Grosso do Sul that has a prevalence equal to approximately $3 \%$ of its population $(10,11)$. Other endemic areas are found within Colombia and Peru $(12,13,14)$. The average age of nonendemic PF symptom onset ranges from 40 to 60 years of age. FS affects a larger number of children and young adults as symptoms usually begin during the second or third decade of life (14). Both sporadic and endemic PF are typically seen equally in men and women and affect those of all races and ethnicities. However, there are populations of FS that may deviate from the norm. For example, epidemiological studies in Tunisia found the female-tomale ratio of incidence rates to be approximately 4 to 1 (9).

\section{Patient History}

Patients usually report a history of blister formation on the skin (Fig. 1). Lesions commonly begin on the trunk, but may also originate as localized lesions on the face or scalp. The patient may be unaware of the blisters because they rupture very easily. In these cases, there may only be a history of superficial sores or areas of crusting. Pain and/or a burning sensation localized to the areas of the lesions may be noted. Unlike pemphigus vulgaris $(\mathrm{PV})$, there is typically no history of oral or other mucosal lesions. The lesions may become widespread. Patients with the mildest form of PF may only report a history of a small, solitary, recurrent scaly and crusty lesion of the face (Fig. 2). In these cases, it may be years before the patient is correctly diagnosed. In cases of PE, patients report the development of lesions in sun-exposed areas of the face, scalp, and upper chest and back-similar to the distribution of lesions seen in lupus erythematosus (LE).

Because multiple drugs have been found to be associated with the development of PF, it is important to thoroughly review the patient's current medications. The most commonly implicated drug is penicillamine, which is a chelating agent used to treat Wilson's disease, lead and arsenic poisoning, and severe active rheumatoid arthritis (15). Drug-associated cases may persist or quickly clear after the offending agent is withdrawn. Various angiotensin-converting enzyme (ACE) inhibitors have also been found to induce pemphigus. Table 1 shows other drugs that have been associated with PF. Most of these drugs contain thiol (-SH) functional groups in their chemical structure while others have disulfide bonds that are cleaved during metabolism to yield thiol groups (16). PF can also be either induced or exacerbated by exposure to ultraviolet light and ionizing radiation $(17,18,19,20)$. 
A growing number of diseases have been associated with PF, including bullous pemphigoid, myasthenia gravis, and other autoimmune diseases $(21,22,23,24)$. A complete past medical history should also be obtained to identify all pre-existing medical conditions of the patient. PF has been associated with certain neoplasms, including B-cell lymphoma, T-cell lymphoma, prostate cancer, and cutaneous squamous cell carcinoma $(25,26,27,28)$. Transition from PF to other forms of pemphigus and vice versa may occur. There have been a few documented cases of patients with clinical, histopathological, and serological features of PV who subsequently underwent a confirmed transition to $\mathrm{PF}(29,30)$. Although both are rare, this is found more commonly than a shift from PF to PV (31).

Non-endemic PF may occur in the neonate via transplacental transit of pathogenic IgG antidsg-1 autoantibodies from a mother with active disease $(32,33,34)$. These cases are uncommon and most neonates born of mothers with PF will not develop active disease (35). A study of 19 mothers with documented FS revealed that all respective babies were born with normal skin (36). Given that the sera of all of the mothers showed high titers of FS autoantibodies, the placenta may act as an immunoadsorbant of unwanted autoantibodies (37). Additionally, dsg-3 has been found to be present in all layers of the epidermis in neonates, including the superficial layer, in contrast to adults, who express dsg-1 superficially and dsg-3 intermediately and basally (38). This expression of dsg-3 in the superficial epidermis is thought to be protective against the formation of blisters induced by PF antibodies in neonates (38).

FS, which has been extensively studied in Brazil, is thought to be triggered by an environmental factor, perhaps from an antigen transmitted by the bite of a hematophagous insect, in genetically-susceptible individuals. The antibodies produced against this unidentified antigen may cross-react with dsg-1, leading to the development of FS. This theory is based on the following observations from endemic areas of Brazil: (1) Specific human leukocyte antigen (HLA) genes have been associated with increased FS susceptibility (39); (2) FS displays geographic and familial clustering; (3) The families typically share a common bedroom in poor living conditions; (4) The living dwellings tend to be infested with blood-feeding arthropods (40); (5) A spike in FS cases occurs after the end of the rainy season when insect breeding conditions are optimal (40); and (6) FS cases tend to decrease as the living conditions improve in endemic areas of Brazil (10). Recent research has focused on the study of a protein transmitted from the saliva of Simulium nigrimanum, a type of black fly (41).

\section{Physical Exam}

The endemic and non-endemic forms of PF typically share the same clinical findings (42). The primary lesions are flaccid, superficial vesicles and bullae of the skin. These lesions may not be seen on examination because of their fragile and subsequent transient nature. More often, only secondary lesions, such as shallow erosions, are seen. Scaling of these lesions is commonly seen, representing the detachment of the overlying stratum corneum from the area of intra-epidermal acantholysis, the stratum granulosum. Most lesions appear on the chest, back, and shoulders (Fig. 3). On certain areas of the body such as the face and scalp, the exudate from the erosive lesions dries quickly, leaving areas of crusting over an erythematous base.

A common clinical finding in PF is a positive Nikolsky's sign. This is performed by applying shear stress to the affected skin, usually by rubbing the periphery of existing primary or secondary lesions. If positive, this tangentially-applied force will result in the separation of the upper epidermal layers from the underlying lower layers. This finding has been shown to be moderately sensitive, but highly specific in diagnosing pemphigus (43). 
In its most severe form, $\mathrm{PF}$ can produce an exfoliative erythroderma characterized by generalized erythema and diffuse scaling of the cutaneous surface (Fig. 4). In these cases, it may also lead to alopecia. These patients require prompt hospitalization to prevent serious and sometimes fatal complications from metabolic instability.

The variant PE combines features of PF and lupus erythematosus. Small, flaccid vesicles and bullae may be seen in a butterfly-distribution on the face, involving the cheeks and nose. Photo-distributed lesions of the scalp, and upper chest and back are also common. Ruptured blisters reveal an erythematous base, and lesions on the face and scalp may have think, greasy scales and yellow crusts. Many patients test positive for anti-nuclear antibodies in their serum (44).

Unusual presentations of PF have previously been described. Several cases have been documented of PF presenting as an acute eruption of multiple hyperpigmented and hyperkeratotic lesions that closely resemble the appearance of seborrheic keratoses $(45,46)$. In cases of sporadic PF in children, patients present with the same primary and secondary lesions, but they often have a distinct configuration having been described as arcuate, circinate, and/or polycyclic (47).

\section{Differential Diagnosis}

The differential diagnosis of endemic and non-endemic PF includes bullous impetigo, IgA pemphigus, $\mathrm{PH}$, drug eruption, subcorneal pustular dermatosis, and lupus erythematosus. If lesions are localized to the face or scalp with abundant scaling and yellow crusting, seborrheic dermatitis may be considered. Papulosquamous diseases, including psoriasis, pityriasis rubra pilaris (PRP), and drug hypersensitivity, should be additional diagnostic considerations for patients presenting with exfoliative erythroderma.

\section{Diagnosis}

There are a variety of diagnostic studies that can be used to support clinical suspicion of PF. Histology and direct immunofluorescence (DIF) requires tissue samples from the patient. Biopsy for DIF should be taken from perilesional skin - normal-appearing skin immediately adjacent to a lesion—since inflamed and blistered skin may lead to the destruction of immune deposits and result in a false-negative study (48). Indirect immunofluorescence (IIF) and enzyme-linked immunosorbent assay (ELISA) studies require patient serum. Ultimately, the diagnosis of PF is based on three criteria: (1) The overall clinical picture, including patient history and physical exam; (2) The histopathological findings of the biopsy; and (3) The presence of autoantibodies as detected by direct and indirect immunofluorescent studies. Neither one of these alone is diagnostic of PF.

\section{Histopathology}

The earliest pre-acantholytic findings in PF are the formation of vacuoles within the intercellular spaces of the granular and/or upper spinous layers of the epidermis (49). Eosinophilic spongiosis of the epidermis may also be seen (50). As PF lesions progress, the vacuoles become larger and eventually lead to subcorneal blister formation within the upper epidermis (Fig. 5). There are variable amounts of acantholytic keratinocytes, neutrophils, and fibrin within the blisters (51). Older PF lesions show evidence of chronic inflammation, including papillomatosis, acanthosis, hyperkeratosis, parakeratosis, and follicular plugging. Keratinocytes of the granular layer display dyskeratotic changes. There is an increase in pigment formation of basal melanocytes. The capillaries of the papillary dermis become dilated. Upper dermal edema may be present to varying degrees. An inflammatory infiltrate composed of small amounts of neutrophils, eosinophils, and lymphocytes may be present in a variable distribution (52). 


\section{Direct Immunofluorescence}

DIF is a special immunostaining procedure that is used to detect antibody and complement deposition within the tissue sample. For diagnosis of any pemphigus disease, its sensitivity has been found to range from $80-95 \%$ (53). DIF becomes positive earlier in the course of disease than IIF and is thus, considered slightly more reliable in detecting the initial presentations of PF (54). PF shows a DIF pattern characterized by fluorescent staining around keratinocytes, which is known as the intercellular space (ICS) staining patternrepresentative of all pemphigus disease. In PF, this is a result of dsg-1-bound antibody on the desmosomes at the keratinocyte cell surface. The intensity of this fluorescent stain in PF may be greater in the upper epidermis due to the increased density of dsg-1 and subsequent antibody deposition in the superficial epidermis (55). Complement component 3 (C3) may also stain at the ICS in PF (56). PE may show staining of both the ICS and the basement membrane zone (BMZ) (57).

\section{Indirect Immunofluorescence}

IIF is a staining technique that uses patient serum to identify antibodies directed against an antigen on a specific type of tissue substrate. It has been found to have a sensitivity ranging between 79-90\% for diagnosing pemphigus disease (53). Human skin is commonly used as substrate for IIF staining in patients suspected of having PF since it has been found to be more sensitive (greater density of dsg-1) whereas monkey esophagus is preferentially used to detect PV because of heightened sensitivity (greater density of dsg-3, the autoantigen target of PV) $(58,59)$. However, the use of both has been found to improve sensitivity to $100 \%$ (60). Like DIF, IIF will show ICS staining in PF with a potential greater fluorescent intensity in the upper epidermis (Fig. 6) (61). IgG subclass staining for PF shows both IgG1 and $\mathrm{IgG} 4$ subclasses are produced against dsg- 1 , with IgG4 being the predominant autoantibody subclass $(62,63)$. IIF titers can be used as an approximate estimate of disease activity in patients (64). For instance, patients with severe disease will typically have high titers and patients with mild disease will have low titers. The direct correlation of disease extent with the level of circulating IgG autoantibody as measured by IIF has been best demonstrated by mouse models of pemphigus (65).

\section{Enzyme-linked immunosorbent assay}

ELISA studies have been found to be a sensitive and specific tool for pemphigus diagnosis. This method uses purified recombinant human dsg-1 to detect PF IgG autoantibodies in patient serum (66). ELISA also provides a quantitative way to measure the amount of circulating autoantibodies (67), which can be used to monitor a patient's response to treatment. One study found that the sensitivity of diagnosing untreated cases of PF was $100 \%$ whereas in treated cases it was $92 \%$ (68). However, the negative cases could represent a successful response to treatment. The threshold for a positive result in this study was chosen to give a specificity of $98 \%$. A larger study found the sensitivity and specificity of detecting dsg-1 autoantibodies in PF patients to be $97.9 \%$ and $98.9 \%$, respectively (69). In endemic regions of FS, the specificity of ELISA is relatively lower since more normal individuals in these areas test positive (increase in false positives) for total IgG anti-dsg-1 autoantibodies (11). However, a positive ELISA result for IgG4 anti-dsg-1 autoantibodies in normal individuals from endemic areas can be used to predict those with preclinical FS who could develop clinical manifestations in the future (70). Unlike the rough estimate of disease severity that IIF provides in humans, ELISA titers have been found to consistently correlate with disease activity throughout the patient's clinical course $(71,72,73,74)$. Therefore, it can be considered the best laboratory analysis for monitoring a patient's response to therapy. 


\section{Biography}

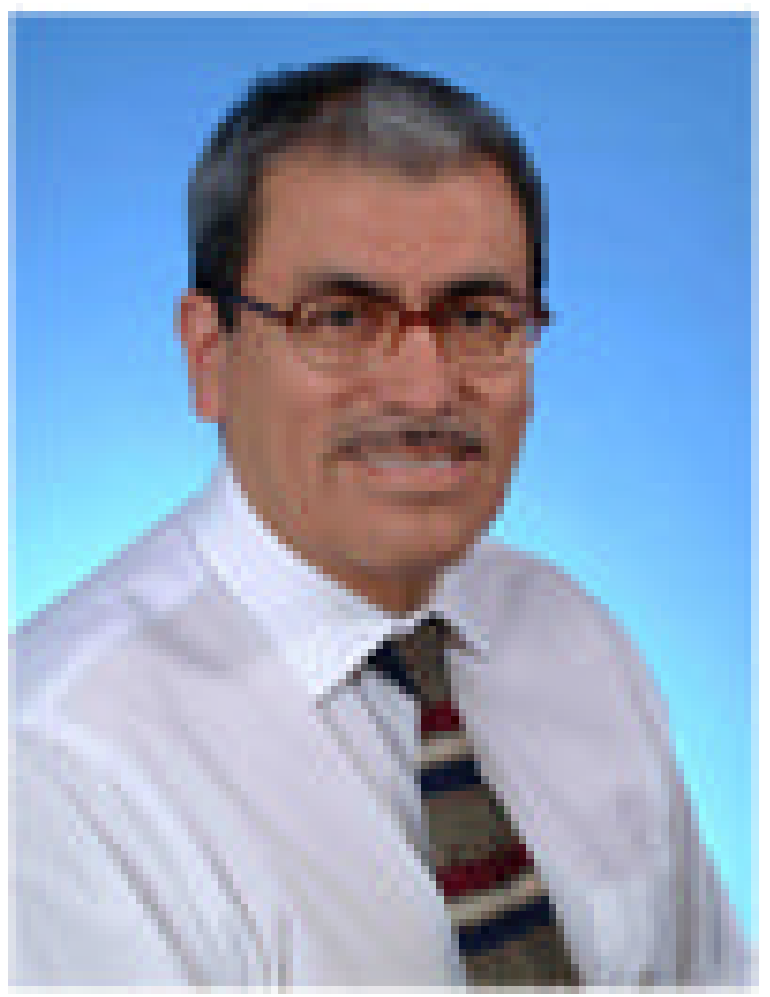

\section{References}

1. Rock B, Martins CR, Theofilopoulos AN, et al. The pathogenic effect of IgG4 autoantibodies in endemic pemphigus foliaceus (fogo selvagem). N Engl J Med. 1989; 320:1463-1469. [PubMed: 2654636]

2. Sekiguchi M, Futei Y, Fujii Y. Dominant autoimmune epitopes recognized by pemphigus antibodies map to the N-terminal adhesive region of desmogleins. J Immunol. 2001; 167:5439-5448. [PubMed: 11673563]

3. Li N, Aoki V, Hans-Filho G, et al. The role of intramolecular epitope spreading in the pathogenesis of endemic pemphigus foliaceus (fogo selvagem). J Exp Med. 2003; 197:1501-1510. [PubMed: 12771179]

4. Rubenstein DS, Diaz LA. Pemphigus antibody induced phosphorylation of keratinocyte proteins. Autoimmunity. 2006; 39:577-586. [PubMed: 17101501]

5. Berkowitz P, Chua M, Liu Z, et al. Autoantibodies in the autoimmune disease pemphigus foliaceus induce blistering via p38 mitogen-activated protein kinase-dependent signaling in the skin. Am J Pathol. 2008; 173:1628-1636. [PubMed: 18988808]

6. Lee HE, Berkowitz P, Jolly PS, et al. Biphasic activation of p38MAPK suggests that apoptosis is a downstream event in pemphigus acantholysis. J Biol Chem. 2009; 284:12524-12532. [PubMed: 19270308]

7. España A, Diaz LA, Mascaró JM Jr. Mechanisms of acantholysis in pemphigus foliaceus. Clin Immunol Immunopathol. Oct.85:83-89. [PubMed: 9325073]

8. Robinson ND, Hashimoto T, Amagai M, et al. The new pemphigus variants. J Am Acad Dermatol. 1999; 40:649-671. [PubMed: 10321591]

9. Bastuji-Garin S, Souissi R, Blum L, et al. Comparative epidemiology of pemphigus in Tunisia and France unusual incidence of pemphigus foliaceus in young Tunisian women. J Invest Dermatol. 1995; 104:302-305. [PubMed: 7829889] 
10. Culton DA, Qian Y, Li N, et al. Advances in pemphigus and its endemic pemphigus foliaceus. J Autoimmun. 2008; 31:311-324. [PubMed: 18838249]

11. Warren SJ, Lin MS, Giudice GJ, et al. The prevalence of antibodies against desmoglein 1 in endemic pemphigus foliaceus in Brazil. Cooperative group on Fogo Selvagem research. N Engl J Med. 2000; 343:23-30. [PubMed: 10882765]

12. Abreu-Velez AM, Hashimoto T, Bollag WB, et al. A unique form of endemic pemphigus in northern Colombia. J Am Acad Dermatol. 2003; 49:599-608. [PubMed: 14512903]

13. Robledo MA, Prada S, Jaramillo D, et al. South American pemphigus foliaceus: study of an epidemic in El Bagre and Nechi, Colombia 1982 to 1986. Br J Dermatol. 1988; 118:737-744. [PubMed: 3401411]

14. Meyer N, Misery L. Geoepidemiologic considerations of auto-immune pemphigus. Autoimmun Rev. 2010; 9:A379-A382. [PubMed: 19895907]

15. Penas PF, Buezo GF, Carvajal I, et al. D-Penicillamine-induced pemphigus foliaceus with autoantibodies to desmoglein-1 in a patient with mixed connective tissue disease. J Am Acad Dermatol. 1997; 37:121-123. [PubMed: 9216536]

16. Brenner S, Bialy-Golan A, Ruocco V. Drug-induced pemphigus. Clin Dermatol. 1998; 16:393397. [PubMed: 9642533]

17. Perry HO, Brunsting LA. Pemphigus foliacaeus. further observations. Arch Dermatol. 1965; 91:10-23. [PubMed: 14229593]

18. Cram DL, Winkelmann RK. Ultraviolet-induced acantholysis in pemphigus. Arch Dermatol. 1965; 92:7-13. [PubMed: 11850959]

19. Aghassi D, Dover JS. Pemphigus foliaceus induced by psoralen-UV-A. Arch Dermatol. 1998; 134:1300-1301. [PubMed: 9801700]

20. Low GJ, Keeling JH. Ionizing radiation-induced pemphigus. Case presentations and literature review. Arch Dermatol. 1990; 126:1319-1323. [PubMed: 2221936]

21. Korman NJ, Stanley JR, Woodley DT. Coexistence of pemphigus foliaceus and bullous pemphigoid. Arch Dermatol. 1991; 127:387-390. [PubMed: 1998370]

22. Ishiko A, Hashimoto T, Shimizu H, et al. Combined features of pemphigus foliaceus and bullous pemphigoid: immunoblot and immunoelectron microscopic studies. Arch Dermatol. 1995; 131:732-734. [PubMed: 7778933]

23. Imamura S, Takigawa M, Ikai K, et al. Pemphigus foliaceus, myasthenia gravis, thymoma and red cell aplasia. Clin Exp Dermatol. 1978; 3:285-291. [PubMed: 737872]

24. Ng PP, Ng SK, Chng HH. Pemphigus foliaceus and oral lichen planus in a patient with systemic lupus erythematosus and thymoma. Clin Exp Dermatol. 1998; 23:181-184. [PubMed: 9894364]

25. Cowley NC, Neill SM, Staughton RCD. Pemphigus foliaceus and non-Hodgkin's lymphoma. Int J Dermatol. 1994; 33:510-511. [PubMed: 7928040]

26. Rybojad M, Leblanc T, Flageul B, et al. Paraneoplastic pemphigus in a child with a T-cell lymphoblastic lymphoma. Br J Dermatol. 1993; 128:418-422. [PubMed: 8494756]

27. Ota M, Sato-Matsumura KC, Matsumura T, et al. Pemphigus foliaceus and figurate erythema in a patient with prostate cancer. Br J Dermatol. 2000; 142:816-818. [PubMed: 10792242]

28. Inaoki M, Kaji K, Furuse S, et al. Pemphigus foliaceus developing after metastasis of cutaneous squamous cell carcinoma to regional lymph nodes. J Am Acad Dermatol. 2001; 45:767-770. [PubMed: 11606932]

29. Kawana S, Hashimoto T, Nishikawa T, et al. Changes in clinical features, histologic findings, and antigen profiles with development of pemphigus foliaceus from pemphigus vulgaris. Arch Dermatol. 1994; 130:1534-1538. [PubMed: 7986127]

30. Tsuji Y, Kawashima T, Yokota K, et al. Clinical and serological transition from pemphigus vulgaris to pemphigus foliaceus demonstrated by desmoglein ELISA system. Arch Dermatol. 2002; 138:95-96. [PubMed: 11790172]

31. Ishii K, Amagai M, Ohata Y, et al. Development of pemphigus vulgaris in a patient with pemphigus foliaceus: Antidesmoglein antibody profile shift confirmed by enzyme-linked immunosorbent assay. J Am Acad Dermatol. 2000; 42:859-861. [PubMed: 10767686] 
32. Walker DC, Kolar KA, Hebert AA, Jordon RE. Neonatal pemphigus foliaceus. Arch Dermatol. 1995; 131:1308-1311. [PubMed: 7503576]

33. Avalos-Díaz E, Olague-Marchan M, López-Swiderski A, et al. Transplacental passage of maternal pemphigus foliaceus autoantibodies induces neonatal pemphigus. J Am Acad Dermatol. 2000; 43:1130-1134. [PubMed: 11100038]

34. Hirsch R, Anderson J, Weinberg JM, et al. Neonatal pemphigus foliaceus. J Am Acad Dermatol. 2003; 49:S187-S189. [PubMed: 12894119]

35. Eyre RW, Stanley JR. Maternal pemphigus foliaceus with cell surface antibody bound in neonatal epidermis. Arch Dermatol. 1988; 124:25-27. [PubMed: 3337542]

36. Rocha-Alvarez R, Friedman H, Campbell IT, et al. Pregnant women with endemic pemphigus foliaceus (Fogo Selvagem) give birth to disease-free babies. J Invest Dermatol. 1992; 99:78-82. [PubMed: 1607681]

37. Swinburne LM. Leucocyte antigens and placental sponge. Lancet. 1970; 2:592-594. [PubMed: 4195550]

38. Wu H, Wang ZH, Yan A, et al. Protection against pemphigus foliaceus by desmoglein 3 in neonates. N Engl J Med. 2000; 343:31-35. roble. [PubMed: 10882766]

39. Moraes ME, Fernandez-Vina M, Lazaro A, et al. An epitope in the third hypervariable region of the DRB1 gene is involved in the susceptibility to endemic pemphigus foliaceus (fogo selvagem) in three different Brazilian populations. Tissue Antigens. 1997; 49:35-40. [PubMed: 9027963]

40. Eaton DP, Diaz LA, Hans-Filho G, et al. Comparison of black fly species on an American reservation with a high prevalence of fogo selvage to neighboring disease-free sites in the state of Mato Grosso do Sul, Brazil. J Med Entomol. 1998; 35:120-131. [PubMed: 9538571]

41. Ribeiro JM, Valenzuela JG, Pham VM, et al. An insight into the sialotranscriptome of Simulium nigrimanum, a black fly associated with fogo selvagem in South America. Am J Trop Med Hyg. 2010; 82:1060-1075. [PubMed: 20519601]

42. Diaz LA, Sampaio SA, Rivitti EA, et al. Endemic pemphigus foliaceus (fogo selvagem): II current and historic epidemiologic studies. J Invest Dermatol. 1989; 92:4-12. [PubMed: 2642512]

43. Uzun S, Durdu M. The specificity and sensitivity of Nikolskiy sign in the diagnosis of pemphigus. J Am Acad Dermatol. 2006; 54(3):411-415. [PubMed: 16488290]

44. Steffen C, Thomas D. The men behind the eponym: Francis E. Senear, Barney Usher, and the Senear-Usher syndrome. Am J Dermatopathol. 2003; 25:432-436. [PubMed: 14501294]

45. Bruckner N, Katz RA, Hood AF. Pemphigus foliaceus resembling eruptive seborrheic keratoses. Arch Dermatol. 1980; 116:815-816. [PubMed: 7396547]

46. Kahana M, Trau H, Schewach-Millet M, et al. Pemphigus foliaceus presenting as multiple giant seborrheic keratoses. J Am Acad Dermatol. 1984; 11:299-300. [PubMed: 6237128]

47. Metry DW, Hebert AA, Jordon RE. Nonendemic pemphigus foliaceus in children. J Am Acad Dermatol. 2002; 46:419-422. [PubMed: 11862179]

48. Mutasim DF, Adams BB. Immunofluorescence in dermatology. J Am Acad Dermatol. 2001; 45:803-822. [PubMed: 11712024]

49. Kouskoukis CE, Ackerman AB. Vacuoles in the upper part of the epidermis as a clue to eventuation of superficial pemphigus and bullous impetigo. Am J Dermatopathol. 1984; 6:183186. [PubMed: 6731731]

50. Osteen FB, Wheeler CE Jr, Briggaman RA, et al. Pemphigus foliaceus. Early clinical appearance as dermatitis herpetiformis with eosinophilic spongiosis. Arch Dermatol. 1976; 112:1148-1152. [PubMed: 952537]

51. Kouskoukis CE, Ackerman AB. What histologic finding distinguishes superficial pemphigus and bullous impetigo? Am J Dermatopathol. 1984; 6:179-181. [PubMed: 6375421]

52. Furtado T. Histopathology of pemphigus foliaceus. Arch Dermatol. 1959; 80:66.

53. Harrist TJ, Mihm MC Jr. Cutaneous immunopathology. The diagnostic use of direct and indirect immunofluorescence techniques in diagnostic dermatopathology. Hum Pathol. 1979; 10:625. [PubMed: 393611]

54. Judd KP, Lever WF. Correlation of antibodies in skin and serum with disease severity in pemphigus. Arch Dermatol. 1979; 115:428-432. [PubMed: 373639] 
55. Rodriguez J, Bystryn JC. Pemphigus foliaceus associated with absence of intercellular antigens in lower layers of epidermis. Arch Dermatol. 1977; 113:1696-1699. [PubMed: 339845]

56. Bhogal B, Wojnarowska F, Black MM, et al. The distribution of immunoglobulins and the C3 component of complement in multiple biopsies from the uninvolved and perilesional skin in pemphigus. Clin Exp Dermatol. 1986; 11:49-53. [PubMed: 3708893]

57. Chorzelski TP, Jablonska S, Blaszczyk M. Immunopathological investigations in the Senear-Usher syndrome (coexistence of pemphigus and lupus erythematosus). Br J Dermatol. 1968; 80:211-217. [PubMed: 4869676]

58. Feibleman C, Stolzner G, Provost TT. Pemphigus: superiority of monkey esophagus in the determination of pemphigus antibody. Arch Dermatol. 1981; 117:561-562. [PubMed: 7027966]

59. Shirakata Y, Amagai M, Hanakawa Y, et al. Lack of mucosal involvement in pemphigus foliaceus may be due to low expression of desmoglein 1. J Invest Dermatol. 1998; 110:76-78. [PubMed: 9424092]

60. Harman KE, Gratian MJ, Bhogal BS, et al. The use of two substrates to improve the sensitivity of indirect immunofluorescence in the diagnosis of pemphigus. Br J Dermatol. 2000; 142:1135-1139. [PubMed: 10848736]

61. Bystryn JC, Abel FL, DeFeo D. Pemphigus foliaceus: subcorneal intercellular antibodies of unique specificity. Arch Dermatol. 1974; 110:857-861. [PubMed: 4613277]

62. Futei Y, Amagai M, Ishii K, et al. Predominant IgG4 subclass in autoantibodies of pemphigus vulgaris and foliaceus. J Dermatol Sci. 2001; 26:55-61. [PubMed: 11323221]

63. Hacker MK, Janson M, Fairley JA, et al. Isotypes and antigenic profiles of pemphigus foliaceous and pemphigus vulgaris autoantibodies. Clin Immunol. 2002; 105:64-74. [PubMed: 12483995]

64. Fitzpatrick RE, Newcomer VD. The correlation of disease activity and antibody titers in pemphigus. Arch Dermatol. 1980; 116:285-290. [PubMed: 7369743]

65. Anhalt GJ, Labib RS, Voorhees JJ, et al. Induction of pemphigus in neonatal mice by passive transfer of IgG from patients with the disease. N Engl J Med. 1982; 306:1189-1196. [PubMed: 7040962]

66. Ishii K, Amagai M, Hall RP, et al. Characterization of autoantibodies in pemphigus using antigenspecific enzymelinked immunosorbent assays with baculovirus-expressed recombinant desmogleins. J Immunol. 1997; 159:2010-2017. [PubMed: 9257868]

67. Crowther JR. ELISA. Theory and practice. Methods Mol Biol. 1995; 42:1-218. [PubMed: 7655571]

68. Harman KE, Gratian MJ, Seed PT, et al. Diagnosis of pemphigus by ELISA: a critical evaluation of two ELISAs for the detection of antibodies to the major pemphigus antigens, desmoglein 1 and 3. Clin Exp Dermatol. 2000; 25:236-240. [PubMed: 10844505]

69. Amagai M, Komai A, Hashimoto T, et al. Usefulness of enzyme-linked immunosorbent assay (ELISA) using recombinant desmogleins 1 and 3 for serodiagnosis of pemphigus. Br J Dermatol. 1999; 140:351-357. [PubMed: 10233237]

70. Qaqish BF, Prisayanh P, Qian Y, et al. Development of an IgG4-based predictor of endemic pemphigus foliaceus (fogo selvagem). J Invest Dermatol. 2009; 129:110-118. [PubMed: 18704107]

71. Aoyama Y, Tsujimura Y, Funabashi M, et al. An experience for ELISA for desmoglein 1, suggesting a possible diagnostic help to determine the initial therapy for pemphigus foliaceus. Eur J Dermatol. 2000; 10:18-21. [PubMed: 10694292]

72. Cheng SW, Kobayashi M, Kinoshita-Kuroda K, et al. Monitoring disease activity in pemphigus with enzyme-linked immunosorbent assay using recombinant desmogleins 1 and 3. Br J Dermatol. 2002; 147:261-265. [PubMed: 12174096]

73. Abasq C, Mouquet H, Gilbert D, et al. ELISA testing of anti-desmoglein 1 and 3 antibodies in the management of pemphigus. Arch Dermatol. 2009; 145:529-535. [PubMed: 19451496]

74. Schmidt E, Dähnrich C, Rosemann A, et al. Novel ELISA systems for antibodies to desmoglein 1 and 3: correlation of disease activity with serum autoantibody levels in individual pemphigus patients. Exp Dermatol. 2010; 19:458-463. [PubMed: 20163452]

75. Kaplan RP, Potter TS, Fox JN. Drug-induced pemphigus related to angiotensin-converting enzyme inhibitors. J Am Acad Dermatol. 1992; 26:364-366. [PubMed: 1569260] 
76. Patterson CR, Davies MG. Pemphigus foliaceus: an adverse reaction to lisinopril. J Dermatolog Treat. 2004; 15:60-62. [PubMed: 14754654]

77. Shelton RM. Pemphigus foliaceus associated with enalapril. J Am Acad Dermatol. 1991; 24:503504. [PubMed: 2061454]

78. Ong CS, Cook N, Lee S. Drug-related pemphigus and angiotensin converting enzyme inhibitors. Australas J Dermatol. 2000; 41:242-246. [PubMed: 11105370]

79. Fujita H, Iguchi M, Watanabe R, et al. Pemphigus foliaceus induced by bucillamine. Eur J Dermatol. 2007; 17:98-99. [PubMed: 17324844]

80. Bae YI, Yun SJ, Lee SC, et al. Pemphigus foliaceus induced by an angiotensin II receptor blocker. Clin Exp Dermatol. 2008; 33:721-723. [PubMed: 18627397]

81. Lee CW, Lim JH, Kang HJ. Pemphigus foliaceus induced by rifampicin. Br J Dermatol. 1984; 111:619-622. [PubMed: 6498095]

82. Lucky PA, Skovby F, Thier SO. Pemphigus foliaceus and proteinuria induced by alphamercaptopropionylglycine. J Am Acad Dermatol. 1983; 8:667-672. [PubMed: 6863624] 


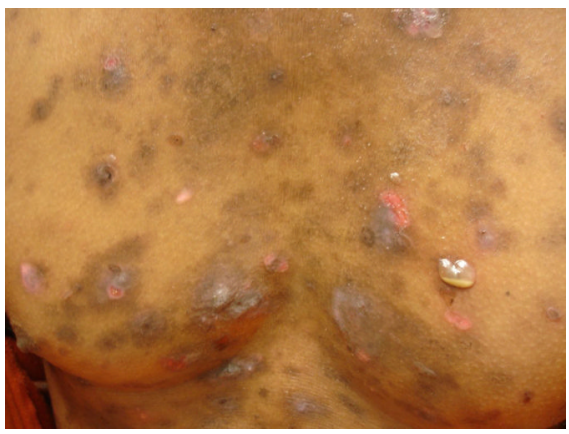

Fig 1.

Intact blister filled with inflammatory exudate on left side of chest. 


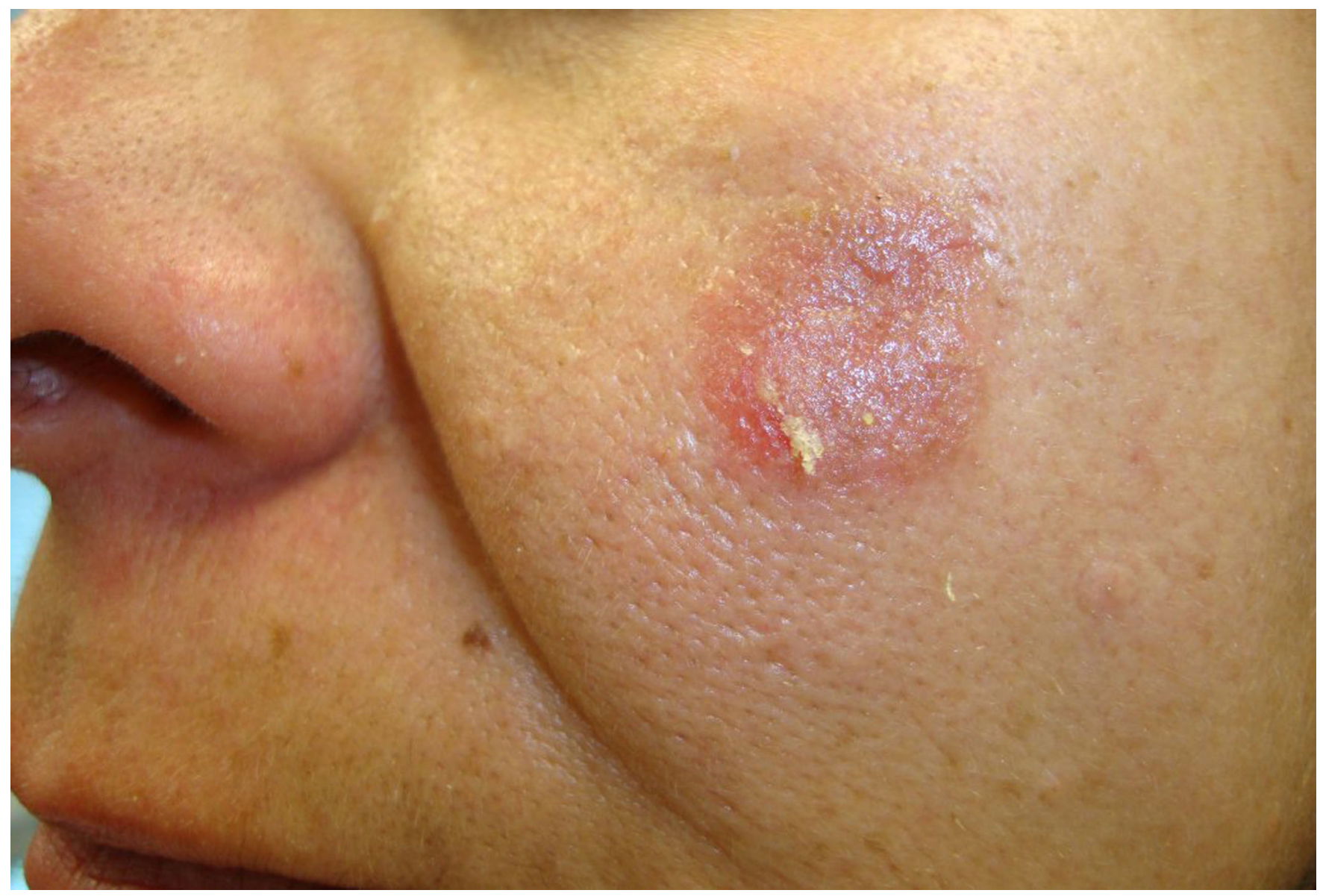

Fig 2.

Isolated scaly, erythematous plaque with peripheral erosion on left cheek. 


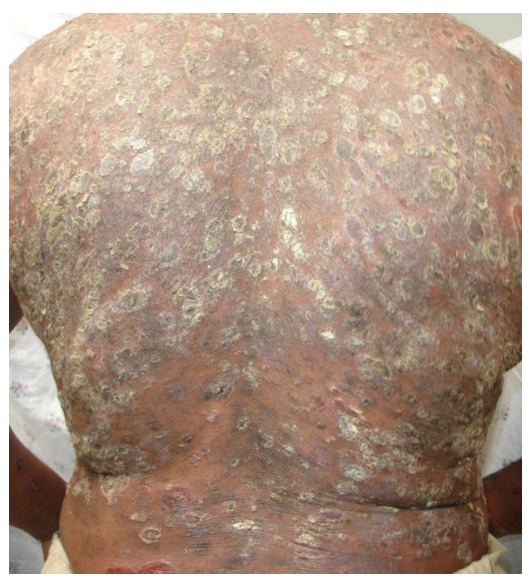

Fig 3.

Disseminated papulosquamous eruption on back evolving from the preceding superficial blisters and secondary erosions of PF. 


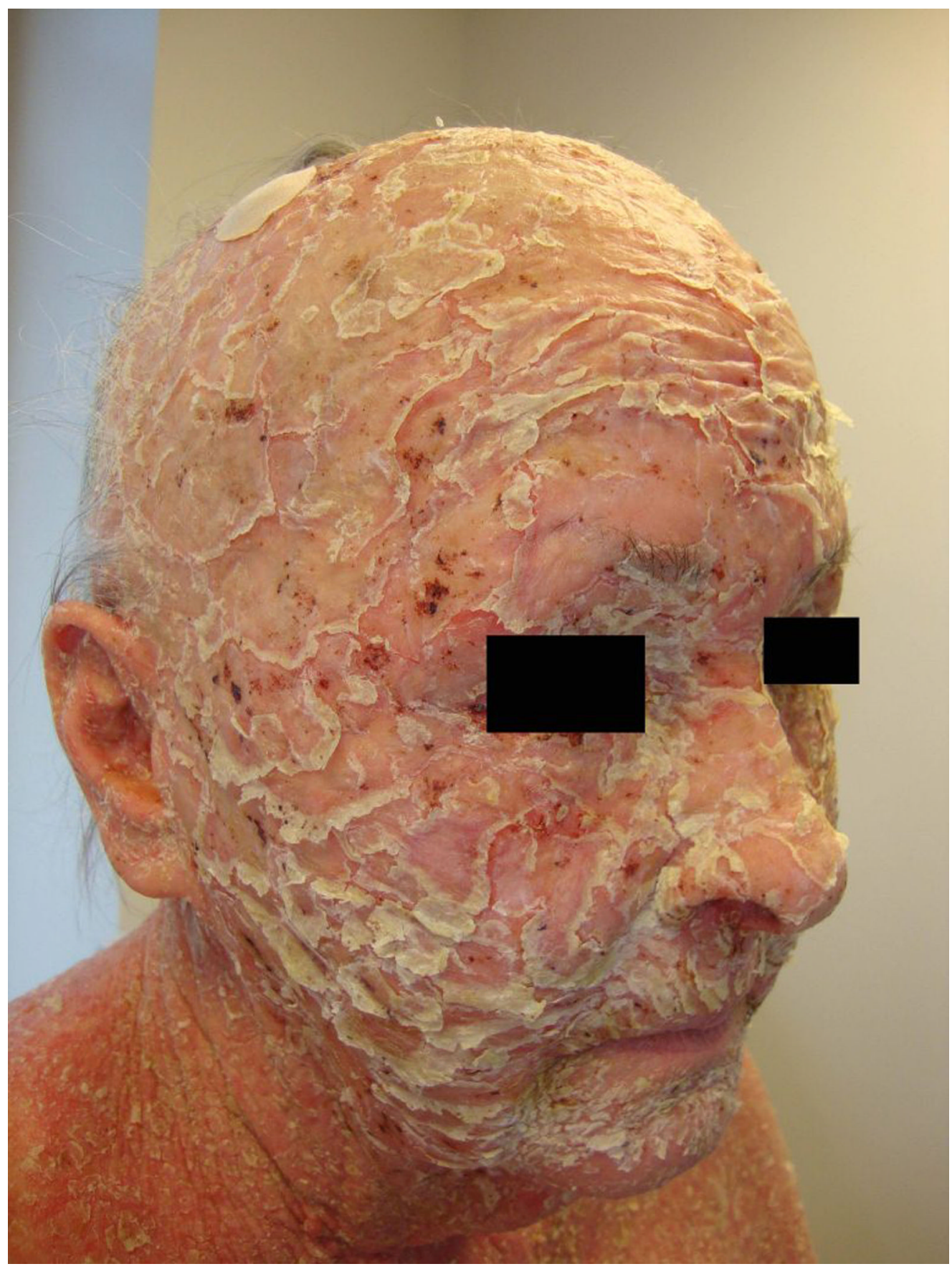

Fig 4.

Severe exfoliative erythroderma. 


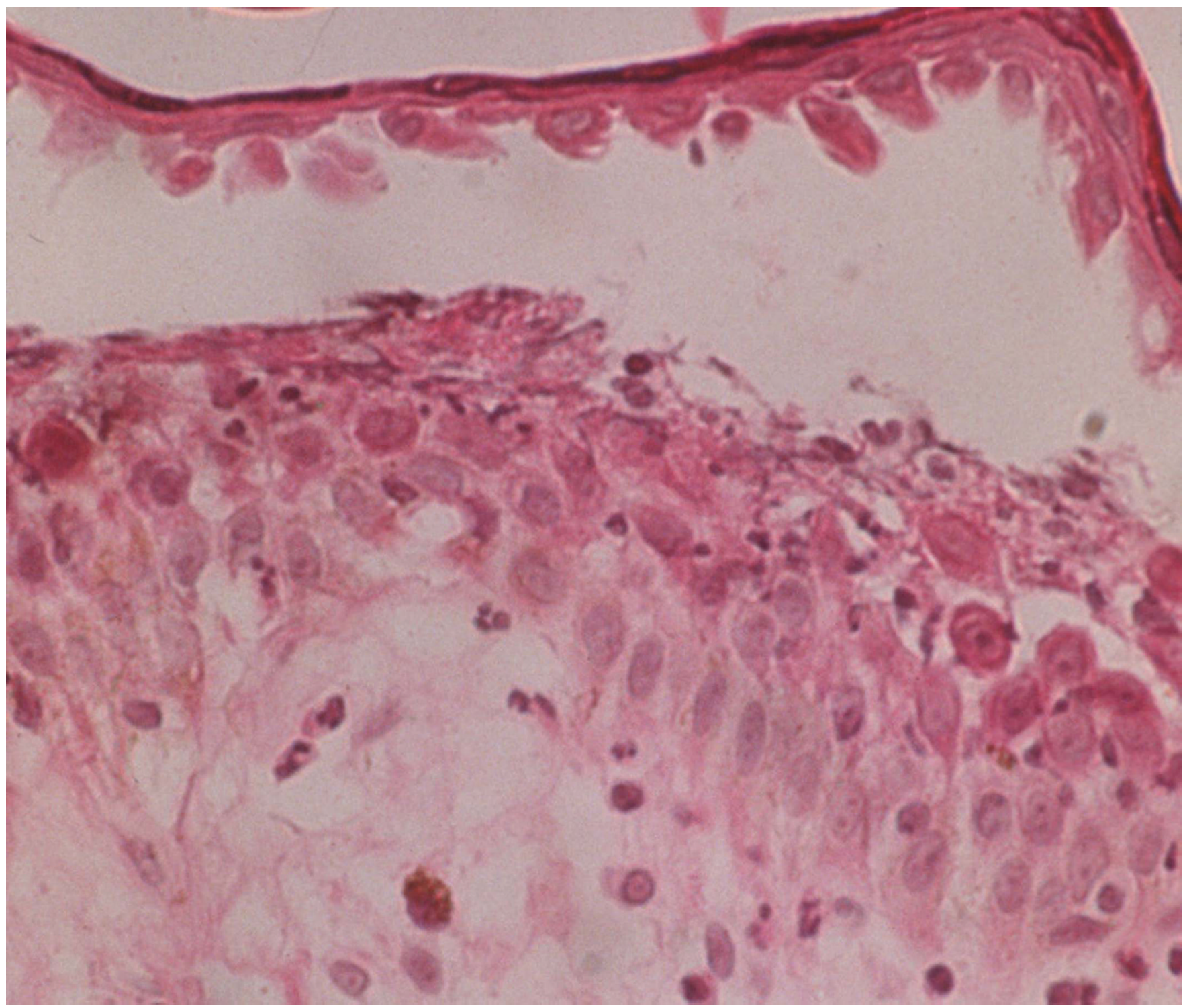

Fig 5.

Biopsy of PF lesion. Subcorneal blister formation due to acantholysis of keratinocytes. 


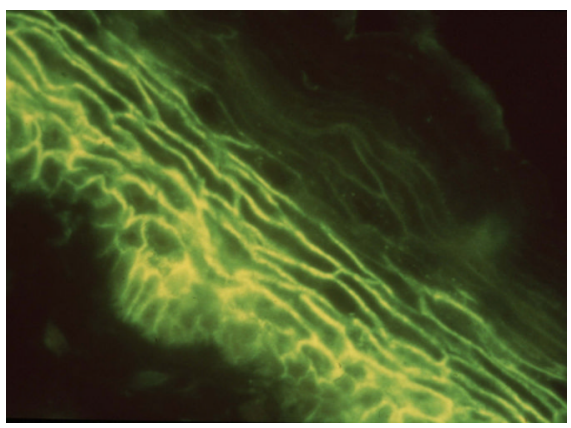

Fig 6.

Positive indirect immunofluorescent staining using PF patient serum on human skin substrate. This staining pattern directed against the intercellular space (ICS) is characteristic of pemphigus. 
Table 1

List of Drugs Associated with PF

\begin{tabular}{|c|}
\hline ACE Inhibitors \\
\hline Captopril (75) \\
\hline Lisinopril (76) \\
\hline Enalapril (77) \\
\hline Fosinopril (78) \\
\hline Disease-Modifying Anti-Rheumatic Drugs (DMARDs) \\
\hline Penicillamine \\
\hline Bucillamine (79) \\
\hline Angiotensin-II Receptor Blockers (ARBs) \\
\hline Candesartan (80) \\
\hline Antibiotics \\
\hline Rifampicin (81) \\
\hline Orphan Drugs \\
\hline Tiopronin (82) \\
\hline
\end{tabular}

